\title{
PENERAPAN PENYUSUNAN LAPORAN KEUANGAN PADA USAHA KECIL DAN MENENGAH (UKM) BERBASIS STANDAR AKUNTANSI KEUANGAN ENTITAS MIKRO KECIL DAN MENENGAH DI KOPI BUBUK ADINDA G19 KOTA LUBUKLINGGAU
}

\author{
${ }^{1}$ Khairunnisah, ${ }^{2}$ Eri Triharyati, ${ }^{3}$ Yuli Nurhayati \\ Program Studi Akuntansi, Universitas Bina Insan, Lubuklinggau \\ E-mail : ${ }^{1}$ nisahkhairunnisahh@gmail.com, ${ }^{2}$ eri_triharyati@univbinainsan.ac.id, \\ 3yuli_nurhayati@univbinainsan.ac.id
}

\begin{abstract}
This research is a research in the coffee bean industry business, namely UKM Kopi Powder Adinda G19 Lubuklinggau City which has not implemented the appropriate preparation of financial reports according to the Financial Accounting Standards for Micro, Small and Medium Entities. This study uses data collection methods, by observing and recording directly at the research site (observation), conducting direct question and answer questions at the source (interview), and documentation by reading literature guidelines. This type of qualitative research and data analysis techniques use descriptive qualitative methods. The results of this study indicate that the preparation of the financial statements of the UKM Kopi Powder Adinda G19 Lubuklinggau City is not suitable, only the format of income and expenditure is in the preparation of the financial statements. The recording is still very simple due to the lack of knowledge regarding the preparation of financial reports according to applicable standards so that the Adinda G19 Ground coffee UKM has not been able to produce financial report compilations that are in accordance with the standards.
\end{abstract}

Keywords : Preparation of Financial Statements, Financial Accounting Standards for Micro, Small and Medium Entities

Abstrak
Penelitian ini adalah penelitian di bidang usaha industri biji kopi yaitu UKM Kopi Bubuk Adinda G19 Kota Lubuklinggau yang mana belum menerapkan penyusunan laporan keuanganya yang sesuai menurut Standar Akuntansi Keuangan Entitas Mikro Kecil dan Menengah. Penelitian ini menggunakan metode pengumpulan data, dengan melakukan pengamatan dan pencatatan secara langsung pada tempat penelitian (observasi), melakukan tanya jawab langsung pada sumber (interview), dan dokumentasi dengan cara membaca pedoman-pedoman literatur. Jenis penelitian kualitatif dan teknik analisis data menggunakan metode kualitatif deskriptif. Hasil dari penelitian ini bahwa penyusunan laporan keuangan UKM Kopi Bubuk Adinda G19 Kota Lubuklinggau belum sesuai, hanya format pendapatan dan pengeluaran saja dalam penyusunan laporan keuanganya. Pencatatan yang dilakukan masih sangat sederhana karena kurangnya pengetahuan mengenai penyusunan laporan keuangan sesuai standar yang berlaku sehingga UKM kopi Bubuk Adinda G19 belum mampu menghasilkan penyusunan laporan keuangan yang sesuai dengan standarnya.

Kata Kunci : Penyusunan Laporan Keuangan, Standar Akuntansi Keuangan Entitas Mikro Kecil dan Menengah 


\section{PENDAHULUAN}

Perekonomian yang ada di negara Indonesia tidak terlepas dari kegiatan ekonomi yang di lakukan oleh perorangan maupun organisasi, usaha yang di lakukan oleh perorangan sering disebut dengan Usaha kecil dan menengah (UKM). Begitu juga banyaknya yang mendirikan UKM di Provinsi Sumatra Selatan Kota Lubuklinggau. Dengan adanya UKM sangat membantu perekonomian yang ada didaerah sekitar, karena dapat mengurangi resiko pengangguran dengan banyak menyediakan lapangan pekerjaan sehingga membantu pemerintah dalam masalah perekonomian yaitu mengurangi angka pengangguran.

Kegiatan UKM sangat berkaitan dengan Akuntansi, Karena Akuntansi merupakan pencatatan yang dapat memberikan informasi berupa perkembangan dan kondisi keuangan UKM sehingga dengan adanya informasi tersebut dapat menjadi bahan evaluasi dari kegiatan UKM tersebut. Akuntansi mempunyai konseptual kerangka, standar, metode, prosedur dan teknik dalam melaporkan suatu kondisi keuangan yang biasa disebut sebagai Laporan Keuangan.

Menurut IAI dalam SAK EMKM (2016:3) tujuan laporan keuangan adalah untuk menyediakan informasi posisi keuangan dan kinerja suatu entitas yang bermanfaat bagi sejumlah besar pengguna dalam pengambilan keputusan ekonomik oleh siapapun yang tidak dalam posisi dapat meminta laporan keuangan khusus untuk memenuhi kebutuhan informasi tersebut.

Akuntansi memberikan informasi yang dapat berguna dalam pengambilan keputusan antara lain mengenai Dasar pertimbangan mengenai pembelian bahan baku serta alat-alat untuk kegiatan produksi, pengambilan keputusan mengenai harga suatu produk, apabalia ingin melakukan pinjaman kepada bank, untuk perkembangan usaha, sebagai pengembangan dan penambahan sumber daya manusia serta penambahan modal usaha. Agar
UKM tersebut berkualitas, harus mengerti dan memahami bagaimana sistem pencatatan di dalam akuntansi, persiapan apa saja yang harus dilakukan, dan bagaimana cara mengaplikasikanya sehingga laporan keuangan yang di hasilkan dapat bermanfaat oleh pihak internal maupun eksternal, karena yang di pergunakan oleh pihak berkepentingan untuk perkembangan usahanya yaitu hasil akhir dalam pencatatan akuntansi yaitu infomasi keuangan.

Melihat situasi dan kondisi saat ini, diperlukanya inovasi dalam penyusunan laporan keuangan yang sesuai dengan standar akuntansi keuangan. Standara tersebut di buat oleh IAI yang dimana Exposure Draft Standar Akuntansi Keuangan Entitas Mikro, Kecil, dan Menengah (ED SAK EMKM) dalam rapatnya pada tanggal 18 Mei 2016 maka telah disetujui oleh Dewan Standar Akuntansi Keuangan. Dengan adanya SAK EMKM pelaku UKM dapat terbantu dengan lebih mudah dalam mengaplikasikan Akuntansi pada usaha mereka. Walaupun laporan keuangan menurut SAK EMKM bisa dikatakan sederhana, namun penyajian laporan keuangan dapat memberikan informasi yang handal.

Laporan keuangan berdasarkan SAK EMKM, laporan keuangan entitas disusun dengan menggunakan asumsi dasar akrual dan kelangsungan usaha, sebagaimana juga digunakan entitas selain entitas mikro, kecil, dan menengah, serta menggunakan konsep entitas bisnis. Bagi skala usaha kecil dan menengah mungkin sedikit rumit untuk di pahami apabila menggunakan SAK umum, sehingga dibuatlah SAK EMKM untuk usaha skala kecil dan menengah dalam pembuatan laporan keuanganya karena lebih mudah di pahami. SAK EMKM menggunakan prinsip kesederhanaan dalam menyajikan laporan keuangan untuk membangun kualitas UKM dalam kegiatan ekonomi yang sangat penting bagi Indonesia.

Adapun objek penelitian yang akan diteliti adalah UKM Kopi Bubuk Adinda G19 Kota 
Lubuklinggau yang bergerak dibidang Industri pengelolaan biji kopi menjadi kopi bubuk asli, yang didirikan pada tahun 2011. Industri dikelolah oleh pemiliknya sendiri yaitu bapak Idham Khalik, ST. Dengan memiliki karyawan bagian kantor dan bagian gudang berjumlah 50 karyawan, penjualan dilakukan secara konsinyasi dan tunai. Sama halnya dengan kondisi pada UKM Industri Kopi Bubuk
Adinda G19 yang belum menerapkan Standar Akuntansi Keuangan Entitas Mikro Kecil dan Menengah pada laporan keuangannya, UKM Kopi Bubuk Adinda G19 hanya Membuat laporan keuanganya dengan format pendapatan dan pengeluaran saja, Berikut contoh gambaran pencatatan beserta contoh transaksi yang di lakukan oleh UKM Kopi Adinda G19 Kota Lubuklinggau.

Tabel. 1

Laporan Pendapatan dan Pengeluaran Kopi Bubuk Adinda G19 Kota Lubuklinggau Bulan Desember 2019

\begin{tabular}{|c|c|c|c|c|c|}
\hline \multicolumn{2}{|c|}{ TGL } & KETERANGAN & PENDAPATAN & $\begin{array}{c}\text { PENGELUARAN } \\
(\mathbf{R n})\end{array}$ & $\begin{array}{c}\text { SALDO } \\
\text { (Rn) }\end{array}$ \\
\hline \multirow[t]{2}{*}{ Des } & 1 & Penjualan & 710.774 .110 & & 710.774 .110 \\
\hline & 1 & $\begin{array}{l}\text { Pembelian } \\
\text { Bahan produksi dan } \\
\text { perlengkapan kantor }\end{array}$ & & 400.080 .000 & 310.694 .110 \\
\hline
\end{tabular}

Sumber : Data Diolah dari UKM Kopi Bubuk Adinda G19 Kota Lubuklinggau

Tabel di atas menjelaskan bahwa UKM Kopi Bubuk Adinda G19 hanya mencatat kas masuk atau sering mereka sebut Pendapatan dan Pengeluaran yang masih sangat sederhana sehingga belum menerapkan penyusunan laporan keuangan sesuai dengan Standar Akuntansi Keuangan Entitas Mikro, Kecil, dan Menengah (SAK EMKM).

\section{TINJAUAN PUSTAKA}

\subsection{Pengertian Laporan keuangan}

Menurut Sofyan Syafri Harapan (2016:105) Laporan keuangan menggambarkan kondisi keuangan dan hasil usaha suatu perusahaan pada saat tertentu atau jangka waktu tertentu. Adapun jenis laporan keuangan yang lazim di kenal: Neraca atau laporan laba/rugi atau hasil usaha, laporan arus kas, laporan posisi keuangan.

Menurut Paidi, Yumaniarti, Dian Wulan Sari (2016:30) Laporan Keuangan yang baik adalah Laporan yang dapat bermanfaat /berguna serta berkualitas sehingga informasi yang
Menggunakan SAK EMKM dalam laporan keuangan diharapkan UKM Kopi Bubuk Adinda G19 dapat mengimplementasikan dalam pembuatan laporan keuanganya yang sesuai dengan standar laporan keuangan yang berlaku, sehingga usaha Industri Kopi yang saat ini di jalankan dapat terdeteksi sehingga bisa menjadi bahan evaluasi untuk periode yang akan datang.

diinginkan di sampaikan oleh pihak menajemen dapat di mengerti oleh user dalam pengambilan keputusan takis atau strategi. Adapun karakteristik dari laporan keuangan menurut Belkaoui Laporan keungan yang baik dan berkualitas memiliki unsur yang relavan, andal, dan komperatif. Laporan keuangan yang relevan terdiri dari nilai peramalan, nilai umpan balik, dan tepat waktu, sedangkan laporan keuangan yang andal terdiri dari keabsahan dapat dibukukan dan netral.

Dari beberapa pengertian menurut para ahli di atas dapat di simpulkan, laporan keuangan adalah suatu catatan informasi 
keuangan perusahaan untuk menggambarkan kondisi keuangan perusahaan.

\subsection{Laporan Keuangan Berdasarkan SAK- EMKM}

Menurut IAI dalam SAK EMKM (2016:89) Penyajian wajar dalam laporan keuangan sesuai dengan syarat SAK EMKM dan pengertian laporan keuangan keuangan yang lengkap untuk entitas dimana penyajian wajar mempunyai syarat penyajianya harus jujur atas pengaruh transaksi, kejadian, dan kondisi lain yang sesuai dengan definisi dan kriteria pengakuan aset, liabilitas, penghasilan, dan beban. Entitas menyajikan secara lengkap laporan keuangan pada akhir setiap periode pelaporan termasuk informasi komparatifnya.

Menurut IAI dalam SAK EMKM (2016:9) laporan keuangan entitas meliputi:

1. Laporan posisi keuangan pada akhir periode

2. Laporan laba rugi selama periode

3. Catatan atas laporan keuangan, yang berisi tambahan dan rincian akun-akun tertentu yang relevan.

\subsection{Indikator Laporan Keuangan Dalam SAK-EMKM}

Menurut IAI (2016:4) adapun indikator sub fokus berupa SAK EMKM dalam penelitian ini yaitu: pengakuan laporan keuangan, pengukuran laporan keuangan, dan penyajian laporan keuangan dengan penjelasan adalah sebagai berikut:

\section{a. Pengakuan}

Pengakuan unsur laporan keuangan merupakan proses pembentukan suatu pos dalam posisi keuangan atau laporan laba rugi yang memenuhi kriteria sebagai berikut:

1) Manfaat ekonomik yang terkait dengan pos tersebut dapat di pastikan akan mengalir ke dalam atau keluar dari entitas dan

2) Pos tersebut memiliki biaya yang dapat diukur dengan andal

\section{b. Pengukuran}

Pengukuran adalah proses penetapan jumlah uang untuk mengakui asset, liabilitas, penghasilan, dan beban di dalam laporan keuangan. Dasar pengukuran unsur laporan keuangan dalam SAK-EMKM adalah biaya historis. Biaya historis suatu aset adalah sebesar jumlah kas atau setara kas yang dibayarkan untuk memperoleh asset tersebut pada saat perolehan. Bila historis suatu liabilitas adalah sebesar jumlah kas atau setara kas yang diterima atau jumlah kas yang di perkirakan akan dibayarkan untuk memenuhi liabilitas dalam pelaksanaan usaha normal.

c. Penyajian

Penyajian wajar dari laporan keuangan sesuai persyaratan SAK EMKM dan pengertian laporan keuangan yang lengkap untuk entitas. Penyajian wajar mensyaratkan penyajian jujur atas pengaruh transaksi, peristiwa, dan kondisi lain yang sesuai dengan definisi dan kreteria pengakuan aset, liabilitas, penghasilan dan beban yang dijelaskan. Pengungkapan diperlukan ketika kepatuhan atas persyaratan tertentu dalam SAK EMKM tidak memadai bagi pemakai untuk memahami pengaruh dari transaksi, peristiwa, dan kondisi lain atas posisi dan kinerja keuangan entias.

Menurut Ikatan Akuntan Indonesia (2018:8) indikator SAK EMKM adalah sebagai berikut yaitu:

a. Laporan akhir keuangan pada akhir periode

b. Laporan laba rugi selama periode

c. Catatan atas keuangan, berisi tambahan dan rincian pos-pos tertentu yang relevan

Menurut jurnal akuntansi dalam situs http://jurnal.pcr.ac.id indikator penggunaan SAK-EMKM dapat diukur antara lain adalah sebagai berikut:
a. Pemahaman mengenai akuntansi
b. Menerapkan akuntansi
c. Pemprosesan data
d. Pencatatan
e. Pencatatan secara manual
f. Pencatatan secara komputerisasi 
g. Latar belakang pendidikan

h. Pencatatan sesuai SAK-EMKM

i. Berpengalaman kurang dari 5 tahun

j. Berpengalaman lebih dari 5 tahun

Dari beberapa penjelasan diatas dapat disimpulkan bahwa indikator yang ada dalam SAK EMKM adalah pengakuan, pengukuran dan penyajian dalam pencatatan laporan posisi keuangan, laporan laba rugi, dan catatan atas laporan keuangan.

\subsection{Penelitian yang Relevan}

Adapun beberapa penelitian terdahulu yang telah dilakukan peneliti sebelumnya yang berkaitan dengan penelitian yang akan dilakukan penelitian tersebut adalah sebagai berikut:

Tabel 2

Penelitian yang Relevan

\begin{tabular}{|c|c|c|c|c|}
\hline No & $\begin{array}{c}\text { Peneliti } \\
\text { Tahun } \\
\text { penelitian }\end{array}$ & Judul Penelitian & $\begin{array}{c}\text { Metode } \\
\text { Penelitian }\end{array}$ & Hasil Penelitian \\
\hline 1. & $\begin{array}{l}\text { Ketut Ari } \\
\text { Warsadi } \\
\text { Dkk/2017 } \\
\text { Universitas } \\
\text { Pendidikan } \\
\text { Ganesha } \\
\text { Singaraja }\end{array}$ & $\begin{array}{l}\text { Penerapan } \\
\text { Penyusunan Laporan } \\
\text { Keuangan Pada } \\
\text { Usaha Kecil dan } \\
\text { Menengah Berbasis } \\
\text { Standar Akuntansi } \\
\text { Keuangan Entitas } \\
\text { Mikro Kecil dan } \\
\text { Menengah pada PT. } \\
\text { Mama Jaya. }\end{array}$ & Kualitatif & $\begin{array}{l}\text { UKM PT. Mama Jaya yang } \\
\text { bergerak di bidang perdagangan } \\
\text { penjualan atau penyaluran bahan } \\
\text { bakar minyak tanah. belum } \\
\text { menerapkan Penyusunan Standar } \\
\text { Akuntansi Keuangan EMKM dalam } \\
\text { Pencatatan Laporan Keuanganya, } \\
\text { PT Mama Jaya Membuat Laporan } \\
\text { Keuanganya Masih sangat } \\
\text { sederhana dan manual yang berisi } \\
\text { Pemasukan dan Pengeluaran saja. }\end{array}$ \\
\hline 2. & $\begin{array}{l}\text { Ivana Nina } \\
\text { Esterlin } \\
\text { Barus dkk } \\
\text { Universitas } \\
\text { of } 17 \\
\text { Agustus } \\
1945 / 2018 \\
\text { Samarinda }\end{array}$ & $\begin{array}{l}\text { Implementasi SAK } \\
\text { EMKM (Entitas } \\
\text { Mikro Kecil dan } \\
\text { Menengah) Pada } \\
\text { UMKM BORNEO } \\
\text { FOOD TRUCK } \\
\text { SAMARINDA } \\
\text { COMMUNITY }\end{array}$ & Kualitatif & $\begin{array}{l}\text { Ukm Food truck adalah usaha kecil } \\
\text { menengah dengan konsep penjualan } \\
\text { makanan dengan menggunakan } \\
\text { sebuah kendaraan, ukm tersebut } \\
\text { belum mengimplementasikan SAK } \\
\text { EMKM Sebagian besar responden } \\
\text { melakukan pencatatan keuangan } \\
\text { sederhana sebatas pengetahuan } \\
\text { pemilik Perusahaan tanpa } \\
\text { berdasarkan standar akuntansi } \\
\text { keuangan. Pencatatan atas } \\
\text { penjualan, pembelian dan } \\
\text { pengeluaran dilakukan dengan } \\
\text { sederhana pada buku biasa dan } \\
\text { tidak teratur serta tidak lengkap. }\end{array}$ \\
\hline 3. & $\begin{array}{l}\text { Rizky } \\
\text { Aminatul } \\
\text { Mutiah } \\
\text { /2019 } \\
\text { Universitas }\end{array}$ & $\begin{array}{l}\text { Penerapan } \\
\text { Penyusunan Laporan } \\
\text { Keuangan pada } \\
\text { UMKM berbasis } \\
\text { SAK EMKM }\end{array}$ & Kualitatif & $\begin{array}{lcr}\text { UMKM } & \text { Silky } & \text { Parijatah } \\
\text { Menunjukkan Bahwa } & \text { Belum } \\
\text { menerapkan SAK EMKM dalam } \\
\text { Penyusunan Laporan Keuanganya } \\
\text { di karenakan terbatasnya pemikiran }\end{array}$ \\
\hline
\end{tabular}




\begin{tabular}{|l|l|l|l|l|}
\hline & $\begin{array}{l}\text { Muhammdi } \\
\text { yah Jember }\end{array}$ & & $\begin{array}{l}\text { tentang mengelolah laporan } \\
\text { keuangan dan terbatasnya jumlah } \\
\text { sumber daya manusia (SDM) yang } \\
\text { tidak memadai dalam penyusunan } \\
\text { laporan keuangan. }\end{array}$ \\
\hline 4 & $\begin{array}{l}\text { Nur diana, } \\
2018\end{array}$ & $\begin{array}{l}\text { Financial accounting } \\
\text { standards for micro, } \\
\text { small and medium } \\
\text { entitas }(\text { SAK- } \\
\text { EMKM) }\end{array}$ & $\begin{array}{l}\text { The population of this research was } \\
\text { the manager and owner of MSME } \\
\text { in malang raya which cover mlang } \\
\text { city, malang regency, and batu city. } \\
\text { The amount of sample according to } \\
\text { augusty (2002) in estimation using } \\
\text { maximum likelihood (ML) is 100- } \\
\text { 200. The respondents were the } \\
\text { manager or owner of MSME. }\end{array}$ \\
\hline
\end{tabular}

\section{METODOLOGI PENELITIAN}

\subsection{Tempat dan Waktu Penelitian}

Penelitian ini dilakukan di UKM Kopi Bubuk Adinda G19 Jl. Moch. Hasan Perum Permata Griya Asri (Perum Polisi) Kel. Muara Enim Lubuklinggau HP./WA. 08117338181 08117334566. Pelaksanaan dalam penelitian ini dimulai dari bulan Januari 2020 hingga bulan Juni 2020.

\subsection{Rancangan Penelitian}

Dalam penelitian ini peneliti menggunakan jenis penelitian dengan pendekatan deskriptif kualitatif. Penelitian dengan pendekatan deskriptif kualitatif merupakan metode yang dapat memberikan gambaran yang berkaitan dengan data sesuai dengan fakta yang di dapat oleh peneliti, Di dalam penelitian ini tidak dilakukan manipulasi data, hanya peneliti menggambarkan suatu data apa adanya sesuai dengan data dan hasil yang di dapat.

Hal ini untuk menunjukkan gambaran dan mendeskripsikan bagaimana UKM Kopi Bubuk Adinda G19 menyajikan laporan keuangannya, sesuai dengan standar akuntansi keuangan. Selain itu peneliti mempelajari buku-buku literatur yang berkaitan dengan masalah penelitian untuk menunjang penyusunan laporan keuangan UKM Kopi Bubuk Adinda G19.

\subsection{Teknik Pengumpulan Data}

Peneliti menggunakan teknik pengumpulan data yaitu wawancara, Penelitian kepustakaan, Observasi dan dokumentasi.

\subsection{Teknik Analisis Data}

Peneliti melakukan teknik analisis data di dalam penelitian ini dengan menggunakan metode kualitatif deskriptif , Penelitian dengan Metode kualitatif ini dimana pengolahan data keuangan pada UKM Kopi Bubuk Adinda G19 hingga data tersebut menjadi sebuah laporan keuangan yang berguna bagi UKM. Metode deskriptif ini merupakan metode yang bertujuan untuk mengetahui sifat serta hubungan yang lebih mendalam antara dua variabel dengan cara mengamati aspek-aspek tertentu secara lebih spesifik untuk memperoleh data yang sesuai dengan masalah yang ada dengan tujuan penelitian, dimana data tersebut diolah, dianalisis, dan diproses lebih lanjut dengan dasar teori-teori yang telah di pelajari sehingga data tersebut dapat ditarik sebuah kesimpulan. 


\section{Hasil dan Penelitian}

\subsection{Profil UKM}

Usaha kecil menengah (UKM) Kopi Bubuk Adinda G19 Kota Lubuklinggau merupakan Usaha yang bergerak di bidang Industri pengelolaan biji kopi menjadi kopi bubuk asli, yang didirikan pada tahun 2011 . Industri dikelolah oleh pemiliknya sendiri yaitu bapak Idham Khalik, ST. Dengan memiliki karyawan bagian kantor dan bagian gudang berjumlah 50 karyawan, penjualan dilakukan secara konsinyasi dan tunai. Awal mulainya usaha kopi ini terinspirasi dari ayah mertua dari Idham Khalik, yang terlebih dahulu menjalankan usaha kopi bubuk yang cukup maju akhirnya bapak Idham Khalik, mencoba untuk mendirikan sebuah usaha yang awalnya hanya usaha rumahan kecil-kecilan akhirnya maju berkembang pesat dan sekarang produk Kopi bubuk Adinda G19 Telah tersebar di berbagai daerah di Provinsi Sumatra Selatan dan Provinsi Bengkulu. Ada beberapa kemasan yang di buat oleh pemilik usaha kopi bubuk Adinda G19 antara lain, 7gram, 20 gram, 30 gram, 65 gram, 95 gram, 100 gram, 160 gram, 250 gram, 360 gram dan 500 gram.

\subsection{Hasil Penelitian}

\subsubsection{Analisis dan Praktek Pencatatan} Laporan keuangan yang di buat oleh UKM Kopi Bubuk Adinda G19

Berdasarkan hasil wawancara yang dilakukan dengan pemilik serta bagian admin keuangan yaitu bapak Idham Khalik dan Mbak Yeni. UKM Kopi Bubuk Adinda G19 yang berdiri di tahun 2011 ini, bertempat di Jl. Moch. Hasan Perum Permata Griya Asri (Perum Polisi) Kel. Muara Enim Lubuklinggau, Sumatra Selatan. Didalam surat legalitas perizinan perusahaan memiliki Modal awal sebesar Rp. 200.000.000 termasuk kedalam perusahaan UMKM tingkat Kecil. Usaha Kecil memiliki kekayaan bersih lebih dari Rp 50.000.000,00 lima puluh juta rupiah sampai dengan paling banyak $\mathrm{Rp} 500.000 .000,00$ lima ratus juta rupiah tidak termasuk tanah dan bangunan tempat usaha

UKM Kopi Bubuk Adinda G19 sendiri memiliki bagian khusus dalam kegiatan produksinya yaitu terdapat bagian produksi dan bagian admin. Kegiatan mengenai pencatatan keuangan atau laporan penjualan masih di lakukan oleh pemilik dan bagian admin keuanganya, bapak Idham Khalik sangat berperan penting dalam hal pencatatan transaksi-transaksi yang terjadi setiap harinya.. Adapun langkah-langkah yang di lakukan oleh UKM Kopi Bubuk Adinda G19 dalam penyusunan laporan keuanganya yaitu

1. Bukti Transaksi Bukti transaksi adalah bukti tertulis tentang terjadinya transaksi keuangan yang di gunakan sebagai sumber pencatatan dalam akuntansi.

Adapun dokumen serta bukti-bukti transaksi yang terdapat di UKM Kopi Bubuk Adinda G19 ini yaitu
a. SPO ( Surat Perintah Order)
b. Kuitansi
c. Nota
d. Faktur
e. Nota Kredit
f. Surat Jalan

2. Pencatatan

Dengan adanya transaksi beserta bukti transaksi selanjutnya UKM Kopi Bubuk Adinda G19 melakukan pencatatan manual dan komputerisasi yang di catat oleh pemilik beserta karyawan bagian 
admin keuanganya, Proses pencatatan laporan keuangan di lakukan setiap hari kerja atau setiap melakukan kegiatan produksi, semua biaya yang keluar di catat di buku pengeluaran kas, sedangkan penjualan di catat di buku penjualan dan program. Berikut contoh dari pencatatan laporan keuangan harian beserta transaksi yang terjadi yang di buat oleh UKM Kopi Bubuk Adinda G19

Tabel 3

Contoh pencatatan Keuangan dan transaksi harian

\begin{tabular}{|c|c|c|}
\hline Saldo Kas Awal & \multicolumn{2}{|l|}{ Rp.13.030.000 } \\
\hline Jumlah Tagihan Masuk Global & \multicolumn{2}{|l|}{ Rp.2.157.500 } \\
\hline Jumlah Setoran dari Adm Marketing (Lama) & \multicolumn{2}{|l|}{ Rp.0 } \\
\hline Jumlah Setoran dari Adm Marketing (Baru) & \multicolumn{2}{|l|}{ Rp.17.957.500 } \\
\hline Jumlah Mutasi Bank & \multicolumn{2}{|l|}{ Rp.9.200.000 } \\
\hline Total Setoran & \multirow{2}{*}{\multicolumn{2}{|c|}{ Rp.27.357.500 }} \\
\hline Jumlah Uang Adm Marketing & & \\
\hline Jumlah Uang Kabag Keuangan & \multicolumn{2}{|l|}{ Rp.30.987.500 } \\
\hline BBM Lk1-Sarolangun Jambi & \multicolumn{2}{|l|}{ Rp.200.000 } \\
\hline BBM Lk2-Cecar & \multicolumn{2}{|l|}{$\frac{\text { Rp.200.000 }}{\text { Rp.120.000 }}$} \\
\hline $\begin{array}{l}\text { Catricdge Printer Epson lx } 310 \text { \& Fotocopy } \\
\text { Kampasing }\end{array}$ & \multicolumn{2}{|l|}{ Rp.30.000 } \\
\hline $\begin{array}{l}\text { Oli Meditran, Gemuk Cobra Vanbell, Kawat } \\
\text { Baja dll }\end{array}$ & \multicolumn{2}{|l|}{ Rp.1,190.000 } \\
\hline Beli Karet Gelang & \multicolumn{2}{|l|}{ Rp.6000 } \\
\hline Pembayaran FIF Group Angs ke-4 & \multicolumn{2}{|l|}{ Rp.1.123.000 } \\
\hline Paper Bag 5 pcs & \multicolumn{2}{|l|}{ Rp.100.000 } \\
\hline Setor Bank & \multicolumn{2}{|l|}{ Rp.20.975.000 } \\
\hline Pembayaran Isi lang Galon (47 Galon) & \multicolumn{2}{|l|}{ Rp.235.000 } \\
\hline BBM Kota - Minibus Tg1 28072020 & Rp.50.000 & \\
\hline BBM Kota - Minibus & Rp.50.000 & \\
\hline $\begin{array}{llll}\text { Retribusi, Parkir, dan Keamanan Lk1- } \\
\text { Sarolangun Jambi }\end{array}$ & Rp.30.000 & \\
\hline Total Pengeluaran & Rp.24.109.000 & \\
\hline Saldo Akhir Kabag Keuangan & Rp.6.878.500 & \\
\hline Jumlah Titipan Kabag Keuangan & Rp.5.736.500 & \\
\hline \begin{tabular}{ll|l} 
Jumlah Titipan & Rp.0
\end{tabular} & Patty Cash & Rp.1.142.000 \\
\hline $\begin{array}{c}\text { Adm Marketing } \\
\text { Total Titipan }\end{array}$ & & \\
\hline
\end{tabular}

Adapun data yang didapat dari hasil wawancara dengan pemilik UKM yaitu bapak Idham Khalik yaitu sebagai berikut: 


\section{Tabel 4}

Data UKM Kopi Bubuk Adinda G19

\begin{tabular}{|c|c|c|}
\hline \multicolumn{3}{|c|}{$\begin{array}{c}\text { UKM KOPI BUBUK ADINDA G19 } \\
\text { KOTA LUBUKLINGGAU } \\
\text { PERIODE } 31 \text { DESEMBER } 2019\end{array}$} \\
\hline No. & KETERANGAN & SALDO \\
\hline 1. & Kas & $\begin{array}{ll}\text { Rp. } & 168.000 .000\end{array}$ \\
\hline 2. & Kas in Bank & Rp. $\quad 487.783 .700$ \\
\hline 3. & Piutang & Rp. 9.600.000.000 \\
\hline 4. & Perlengkapan & $\begin{array}{ll}\text { Rp. } & 189.250 .000 \\
\end{array}$ \\
\hline 5. & Asuransi & Rp. $\quad 67.980 .000$ \\
\hline 6. & Penjualan & Rp. 9.326.213.550 \\
\hline 7. & Beban Angkut Penjualan & Rp. $\quad 250.000 .000$ \\
\hline 8. & Peralatan & $\begin{array}{ll}\text { Rp. } & 355.890 .000\end{array}$ \\
\hline 9. & Mesin & $\begin{array}{ll}\text { Rp. } & 85.000 .000 \\
\end{array}$ \\
\hline 10. & Kendaraan & $\begin{array}{ll}\text { Rp. } & 650.000 .000\end{array}$ \\
\hline 11. & Akumulasi Penyusutan Kendaraan dan Mesin & Rp. $\quad 138.500 .000$ \\
\hline 12. & Hutang Usaha & Rp. $\quad 400.000 .000$ \\
\hline 13. & Tanah & Rp. $\quad 549.800 .000$ \\
\hline 14. & Hutang Bank & Rp. 1.000.000.000 \\
\hline 15. & Modal & Rp. 6.868.949.650 \\
\hline 16. & Pembelian & Rp. 3.037.687.000 \\
\hline 17. & Beban Angkut Pembelian & Rp. 295.300 .000 \\
\hline 18. & Beban Gaji & Rp. 1.400.000.000 \\
\hline 19. & Beban Listrik & Rp. $\quad 10.000 .000$ \\
\hline 20. & Beban Iklan & 24.000 .000 \\
\hline 21. & Beban Pemeliharaan & $\begin{array}{ll}\text { Rp. } & 4.000 .000 \\
\end{array}$ \\
\hline 22. & Beban Penyusutan Peralatan & Rp. $\quad 88.972 .500$ \\
\hline 23. & Beban Bunga & $\begin{array}{ll}\text { Rp. } & 250.000 .000 \\
\end{array}$ \\
\hline 24. & Beban Operasional & $\begin{array}{ll}\text { Rp. } & 170.000 .000 \\
\end{array}$ \\
\hline 25. & Beban Bahan Bakar Minyak & $\begin{array}{ll}\text { Rp. } & 50.000 .000 \\
\end{array}$ \\
\hline
\end{tabular}

Sumber (data diolah tahun 2019)

\subsection{Pembahasan}

\subsubsection{Penyusunan Laporan keuangan}

Laporan keuangan menurut SAK- EMKM memiliki tiga laporan keuangan antara lain yaitu.

a. Laporan Laba rugi

Tabel 5

Laporan Laba Rugi

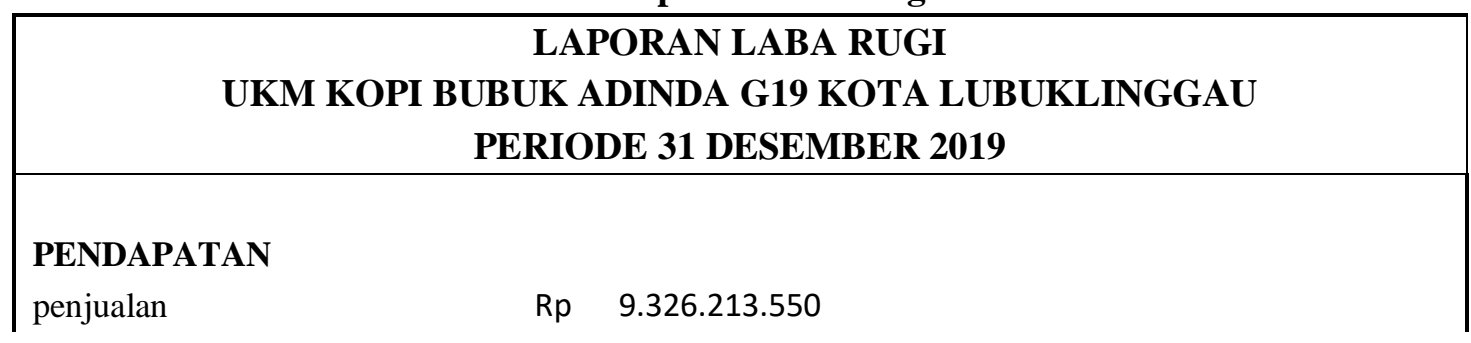




beban angkut penjualan
PENJUALAN BERSIH
Pembelian
beban angkut pembelian
PEMBELIAN BERSIH
LABA KOTOR
BEBAN USAHA
beban gaji
beban listrik
beban iklan
beban pemeliharaan
beban bahan bakar
beban peny. Peralatan
beban bunga
beban operasional

JUMLAH BEBAN

LABA BERSIH TIDAK ADA

PAJAK

\section{LABA BERSIH}

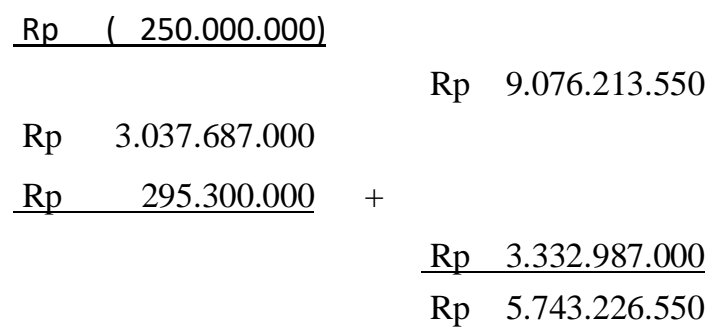

\begin{tabular}{cr}
$\mathrm{Rp}$ & 1.400 .000 .000 \\
$\mathrm{Rp}$ & 10.000 .000 \\
$\mathrm{Rp}$ & 24.000 .000 \\
$\mathrm{Rp}$ & 4.000 .000 \\
$\mathrm{Rp}$ & 50.000 .000 \\
$\mathrm{Rp}$ & 88.972 .500 \\
$\mathrm{Rp}$ & 250.000 .000 \\
$\mathrm{Rp}$ & 170.000 .000 \\
\hline
\end{tabular}

Rp $\quad 1.996 .972 .500$

Rp $\quad 3.746 .254 .050$

Rp 3.746.254.050

Sumber (Data diolah tahun 2019)

b. Laporan Posisi Keuangan (Neraca)

Tabel 6

Laporan Posisi Keuangan (Neraca)

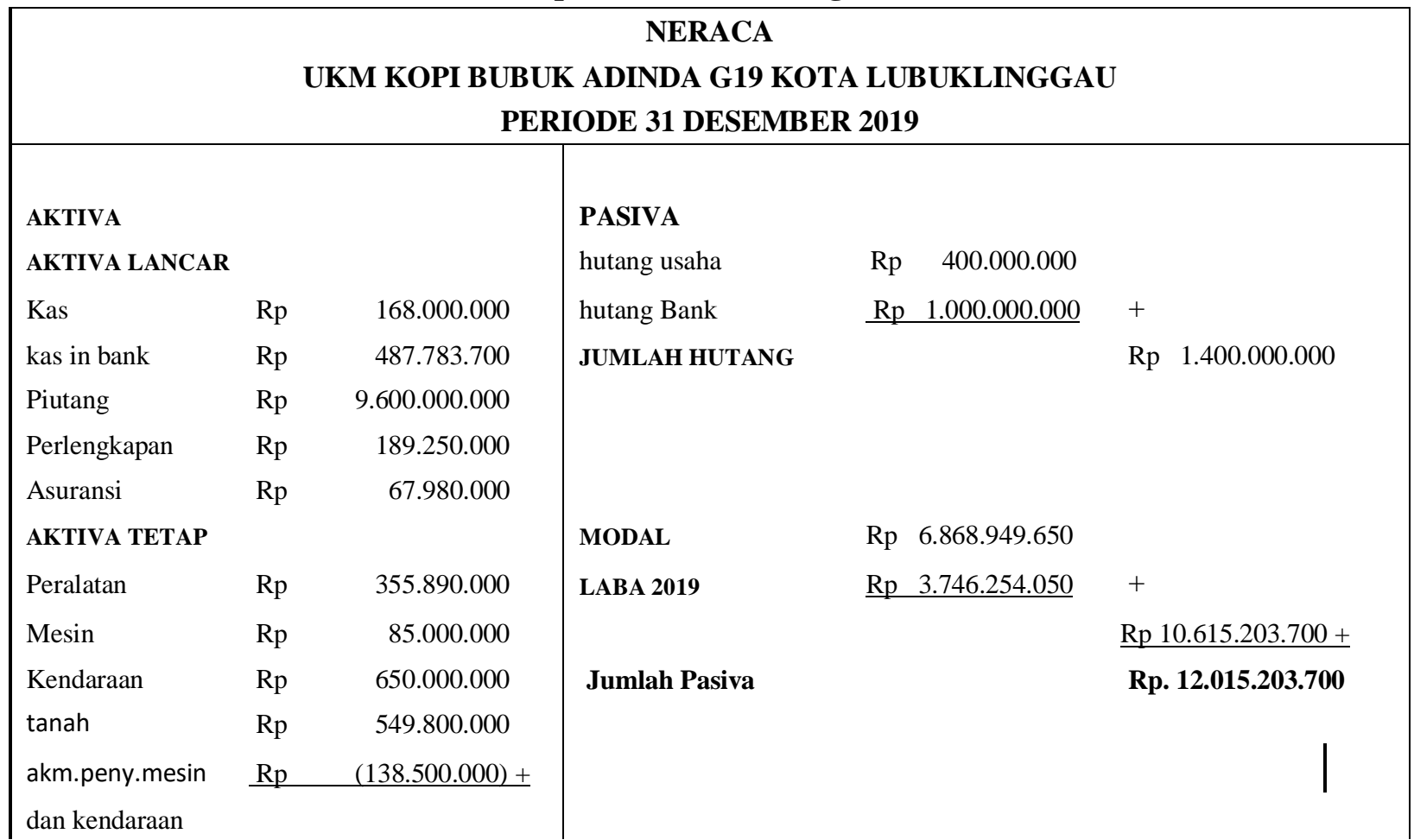




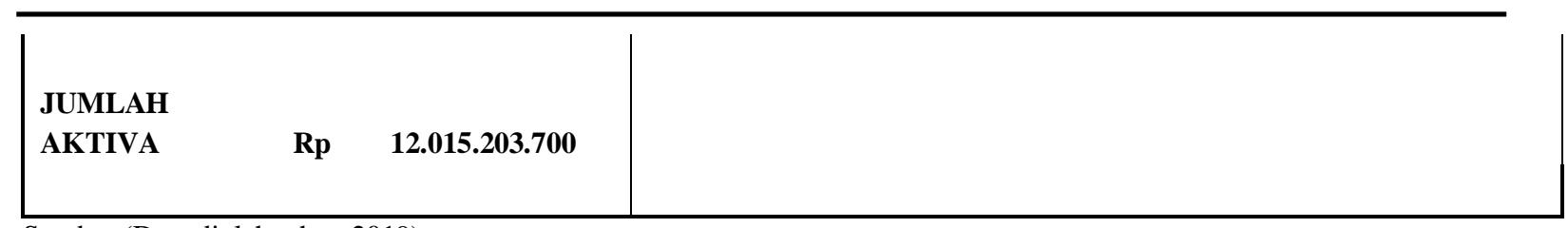

Sumber (Data diolah tahun 2019)

c. Catatan Atas Laporan keuangan

Tabel 7

Catatan Atas Laporan Keuangan

Catatan Atas Laporan Keuangan

Periode 31 Desember 2019

UKM Kopi Bubuk Adinda G19 Kota Lubuklinggau

1. Umum

UKM Kopi Bubuk Adinda G19 Kota Lubuklinggau didirikan pada tahun 2011 di Jln Moch. Hasan Perum Permata Griya Asri Blok. G No. 19 Kelurahan Mura Enim Kecamatan Lubuklinggau Barat 1 Kota Lubuklinggau Provinsi Sumtra Selatan berdasarkan Surat Izin Usaha Industri Kecil dengan nomor 000392/06-12/SIUP/DPM-PTSP/VIII/2018 secara resmi telah memiliki surat Izin usaha industri yang di terbitkan langsung oleh Dinas Penanaman Modal dan Pelayanan Terpadu Satu Pintu jalan yos sudarso No. 05 Kelurahan Majapahit Kecamatan Lubuklinggau timur 1 Telp. (0733) 322173 Fax. (0733) 322173 Kode Pos 31626. UKM Kopi Bubuk Adinda G19 merupakan perusahaan yang bergerak di bidang usaha industri atau manufaktur yang mana mengolah biji kopi menjadi Kopi bubuk asli, UKM Kopi Bubuk Adinda G19 juga telah memenuhi kriteria yang sesuai dengan UU Nomor 20 Tahun 2008 termasuk sebagai Entitas Mikro Kecil dan

Menengah.

2. IKHTISAR KEBIJAKAN AKUNTANSI PENTING

a. Pernyataan Kepatuhan

Penyusunan laporan keuangan di buat sesuai dengan Standar Akuntansi Keuangan Entitas Mikro Kecil dan Menengah (SAK EMKM)

b. Dasar Dalam Penyusunan

Dasar dalam Penyusunan Laporan keuangan adalah dengan biaya historis dan menggunakan asumsi dasar akrual. Mata uang Rupiah yang digunakan dalam penyusunan Laporan Keuangan

c. Piutang Usaha

Piutang usaha yang disajikan Sesuai dengan besarnya tagihan

d. Aset Tetap

Aset Tetap yang dimiliki UKM Kopi Bubuk Adinda G19 di susutkan dengan menggunakan metode Garis Lurus tanpa nilai residu sesuai dengan peraturan Menteri yang ada pada Nomor 96/PMK.03/2009.

e. Pembelian

Nominal Pembelian yang disajikan sesuai dengan jumlah yang harus dibayarkan.

f. Pengakuan Pendapatan dan Beban

Pendapatan dalam penjualan diakui ketika tagihan di keluarkan

dan beban diakui apabila sedang terjadi.

g. Beban Penyusutan

Nominal Beban Penyusutan disajikan menggunakan Metode garis lurus tanpa nilai residu 
3. Kas Tahun 2019

4. Kas In Bank

5. Piutang Usaha Tahun 2019

6. Perlengkapan

7. Asuransi

8. Peralatan

9. Mesin
Rp. 168.000.000

Rp. 487.783 .700

Rp 9.600.000.000

Rp. 189.250 .000

Rp. $\quad 67.980 .000$

Rp. 355.890 .000

Rp. 85.000.000

mesin yang dimiliki oleh UKM Kopi Bubuk Adinda G19 berjumlah 6 buah dengan harga yang berbeda, mesin A Rp. 22.000.000, mesin B Rp. 15.000.000, mesin C Rp. 6.000.000, mesin D Rp. 6.000.000, mesin E Rp. 18.000.000, mesin F Rp. 18.000.000.

10. Kendaraan

Rp. 650.000 .000

Kendaraan berupa mobil yang di miliki UKM Kopi Bubuk Adinda G19 berjumlah 4 kendaraan

11. Tanah

12. Akumulasi Penyusutan Aktiva Tetap Berupa Mesin dan Kendaraan

aktiva tetap mesin 10 tahun dengan menggunakan metode garis lurus tanpa nilai residu $100 \% / 10=10 \%$ x Rp. $85.000 .000=$ Rp. 8.500.000. penyusutan 4 kendaraan berupa mobil menggunakan metode garis lurus tanpa nilai residu $100 \% / 5$ tahun $=20 \% \times \mathrm{Rp} .650 .000 .000=$ Rp. 130.000.000. Jadi akumulasi penyusutan aktiva tetap mesin dan kendaraan berjumlah Rp. 138.500.000.

13. Jumlah Aktiva

Rp. 12.015.203.700

14. Utang Usaha

Rp. $\quad 400.000 .000$

15. Utang Bank

Rp. 1.000 .000 .000

16. Jumlah Kewajiban/Utang

Rp. 1.400 .000 .000

17. Modal

Rp. 6.868 .949 .650

18. Jumlah Pasiva

Rp. 12.015.203.700

19. Pendapatan Penjualan

Penjualan Tahun 2019
Rp. $\mathbf{5 4 9 . 8 0 0 . 0 0 0}$

Rp. 138.500 .000 
20. Beban angkut Penjualan

21. Penjualan Bersih

22. Pembelian

23. Beban Angkut Pembelian

24. Pembelian Bersih

25. Laba Kotor

26. Beban

Beban Gaj

Beban Listrik

Beban Iklan

Beban Pemeliharaan

Beban Bahan Bakar Minyak

Beban Peny. Peralatan

Beban bunga

Beban Operasioanl

JUMLAH BEBAN
Rp. 250.000 .000

Rp. 9.076.213.550

Rp. 3.037.687.000

Rp. 295.300.000

Rp. 3.332.987.000

Rp. 5.743.226.550

Rp. 1.400 .000 .000

Rp. $\quad 10.000 .000$

Rp. $\quad 24.000 .000$

Rp. $\quad 4.000 .000$

Rp. $\quad 50.000 .000$

Rp. $\quad 88.972 .500$

Rp. $\quad 250.000 .000$

Rp. $\quad 170.000 .000$

Rp. 1.996.972.500

27. Laba Bersih Tahun 2019

Rp. 3.746.254.050

\section{KESIMPULAN}

Berdasarkan dari hasil dan pembahasan penyusunan laporan keuangan yang ada di UKM Kopi Bubuk Adinda G19 Kota Lubuklinggau belum menerapkan penyusunan laporan keuangan yang sesuai dengan standarnya yaitu Standar Akuntansi Keuangan Entitas Mikro Kecil dan Menengah yang antara lain laporan Keuangan yang sesuai standarnya yaitu Laporan Laba Rugi, Laporan Posisi Keuangan dan Catatan atas Laporan Keuangan sedangkan penyusunan laporan keuangan UKM Kopi Bubuk Adinda G19 masih sangat sederhana dengan format pendapatan dan pengeluaran saja.

\section{SARAN}

Dalam penyusunan laporan keuangan Seharusnya pihak UKM Kopi Bubuk Adinda
G19 mencoba untuk menggunakan standar ini dalam penyusunan laporan keuanganya yaitu standar SAK-EMKM karena standar ini sangat cocok karena lebih sederhana dibandingankan dengan standar yang lainya dan agar pihak UKM dapat melihat berapa besar laba dan kerugian yang ada di setiap priodenya, didalam laporan keuangan laba rugi, neraca dan catatan atas laporan keuangan pihak UKM juga dapat melihat keseimbangan antara kekayaan dan kewajiban pada saat proses produksi berlangsung.

\section{DAFTAR PUSTAKA}

[1] Ikatan Akuntan Indonesia (IAI). 2018. Standar Akuntansi Keuangan Entitas, Mikro, kecil dan Menengah. Cetakan Ke-

2. GrhaAkuntan Jakarta : IAI. 
[2] Ikatan Akuntan Indonesia. (2017). Standar Akuntansi Keuangan (Statement of Financial Accounting Standards). In Ikatan Akuntansi Indonesia.

[3] Irham Fahmi. 2015. Analisis Laporan Keuangan. Cetakan Ke-5. Bandung : Alfabeta, Cv dan Fahmi, I. (2015). Manajemen Investasi Teori dan Soal Jawab. In Inflasi dan Investasi: Vol. Edisi 2 (Issue Penerbit: Salemba Empat). https://doi.org/10.1007/s10304-010-0358$\underline{x}$.

[4] Juliansyah Noor. 2017. Metodologi Penelitian. Cetakan Ke-7. Jakarta : Kencana.

[5] Wiratna Suwarjeni. 2017. Analisis Laporan Keuangan. Cetakan Ke-1. Yogyakarta : Pusataka Baru Press.

[6] Sofyan Syafri Harahap. 2016. Analilis Kritis Laporan Keuangan. Cetakan Ke13. Jakarta : Pt. Raja Grafindo Persada.

[7] Indonesia, I. A. (2016). Standar Akuntansi Keuangan Entitas Mikro, Kecil, dan Menengah. SAK EMKM, 4, 2017-2019. http://russellbedford.co.id/foto/Newsletter Russell Bedford SBR Edisi No. 4, 2017.pdf.

[8] Rawun, Y., \& Tumilaar, O. N. (2019). Penerapan Standar Akuntansi Keuangan EMKM Dalam Penyusunan Laporan Keuangan pada UMKM (Suatu Studi UMKM Pesisir Di Kecamatan Malalayang Manado). Jurnal Akuntansi Keuangan Dan Bisnis. https://doi.org/10.35143/jakb.v12i1.2472

[9] Sugiyono. (2017). MetodePenelitian Kuantitatif, Kualitatif dan R\&D. Bandung: PT Alfabet. Sugiyono. (2017). MetodePenelitian Kuantitatif, Kualitatif
Dan R\&D. Bandung: PT Alfabet., 53(9), 1689-1699.

https://doi.org/10.1017/CBO9781107415 $\underline{324.004 .}$.

[10] Paidi, Yumaniarti, Dian Wulan Sari. 2016. Membuat Laporan Keuangan Menggunakan MYOB Versi 19.6. Jakarta Selatan : Salemba Empat.

[11] Waren, Carl S., dkk, 2015. Pengantar Akuntansi Adaptasi Indonesia, Jakarta : Salemba Empat. www, depkop.go.id.

[12] 2017. Fakhri Anshori. SAK-EMKM. (Online)

https://fakhrianshori.wordpress.com/201 7/10/06/sak-emkm/.

[13] 2017. Akuntan Indonesia. Prinsip SAKEMKM.

(online) http://akunthink.blogspot.com/2017/06/5 -prinsip-dasar-akuntansi-yangberlaku.html.

[14] 2011. Dhia. Standar Akuntan Keuangan. (online) https://dhiasitsme.wordpress.com/2011/1 0/25/standar-akuntansi-keuangan-sak/.

[15] 2018. Dwi Martini. Faktor Faktor Yang Menpengaruhi SAK-EMKM. (online) http://dwimartani.com/standar-akuntansientitas-kecil-menengah-makrosakemkm/.

[16] Akuntan Indonesia. Metode SAKEMKM. (online) http://akuntansipedia.com/perbedaanpsak-dan-sak-etap-2/\# 